\title{
Modeling the physicochemical properties of orange beverage emulsion as function of main emulsion components using response surface methodology.
}

\begin{abstract}
The effect of main beverage emulsion components namely Arabic gum $(7-13 \% \mathrm{w} / \mathrm{w})$, xanthan gum $(0.1-0.3 \% \mathrm{w} / \mathrm{w})$ and orange oil $(6-10 \% \mathrm{w} / \mathrm{w})$ on physicochemical properties of orange beverage emulsion was determined by using a three-factor central composite design $(C C D)$. The reduced models with high $\mathrm{R} 2(\geqslant 0.80)$ values and non significant $(\mathrm{p}>.05)$ lack of fit were significantly $(\mathrm{p}<.05)$ fitted to the experimental data, thus ensuring a satisfactory fitness of the regression models relating the response to independent variables. The quadratic effect of xanthan gum had a significant $(\mathrm{p}<.05)$ term in all reduced models. The independent variables had the most significant $(\mathrm{p}<.05)$ effect on turbidity loss rate and viscosity ratio. The overall optimum region resulted in the desirable orange beverage emulsion was predicted at a combined level of $13 \%(\mathrm{w} / \mathrm{w})$ Arabic gum, $0.3 \%(\mathrm{w} / \mathrm{w})$ xanthan gum and $10 \%(\mathrm{w} / \mathrm{w})$ orange oil.
\end{abstract}

Keyword: Emulsion stability; Viscosity; Fluid behavior; æ-Potential; Electrophoretic mobility; Orange beverage emulsion; Response surface methodology. 